\title{
THE MEANS OF ANALYSIS AND EVALUATION FOR CORPORATE PERFORMANCES
}

\author{
Tewolde Melles Hagos ${ }^{1}$ \\ Gubán Pal ${ }^{2}$
}

\begin{abstract}
The aim of this paper is to show the concept of corporate performance as a measure of total corporate effectiveness and efficiency and to analyze the components of total corporate performance and define the critical variables affecting each of them.

The main objective is to compare different approaches to the issue of corporate performance analysis [evaluation], and to present cases of corporations applying successful and less successful total performance schemes, as well as to develop an integrated approach to corporate performance analysis and define its organizational, informational, and behavioural requirements.
\end{abstract}

Key words: SWOT analysis, EVA, Balanced Scorecard, customer, internal process, learning and innovation and financial performance, as well as ratio analysis.

JEL codes: L25

\section{Introduction}

Corporate performance management is a set of management and analytic processes that enable the performance of an organization to be managed with a view to achieving one or more preselected goals. It is often comprised within approaches to business process management.

Business performance management has three main activities:

1. the selection of goals

2. the consolidation of measurement information relevant to an organization's progress against these goals,

3. the interventions made by managers in light of this information with a view to improving future performance against these goals.

Although presented here sequentially, typically all three activities will run concurrently, with the interventions made by managers affecting both the choice of goals, the measurement information monitored, and the activities being undertaken within the organization.

Because business performance management activities in large organizations often involve the collation and reporting of large volumes of data, many software vendors, particularly those offering "business intelligence" tools, market products intended to assist in this process. As a result of this marketing effort, business performance management is often (wrongly) seen as being an activity that relies on software systems to work, and many definitions of business performance management explicitly suggest software as being a necessary component of the approach.

Since 1992, business performance management has been strongly influenced by the rise of the Balanced Scorecard framework. It is common for managers to use the Balanced Scorecard framework to clarify the goals of an organization, to identify how to track them, and to structure the mechanisms by which interventions will be triggered. These steps are the same as those that are found in CPM (corporate performance management), and as a result Balanced Scorecard is often used as the basis for business performance management activity with organizations. In the past,

\footnotetext{
${ }^{1}$ Prof. Dr , Harsanyi Janos College, Budapest Email: melles.hagos@hjf.hu

${ }^{2}$ Associated Professor, Harsanyi Janos College, Budapest Email: guban.pal@hjf.hu
} 
owners have sought to drive strategy down and across their organizations, they have struggled to transform strategies into actionable metrics and they have grappled with meaningful analysis to expose the cause-and-effect relationships that, if understood, could give profitable insight to their operational decision-makers.

\section{History}

Reference to non-business performance management occurs in Sun Tzu's The Art of War. Sun Tzu claims that to succeed in war, one should have full knowledge of one's own strengths and weaknesses and full knowledge of one's enemy's strengths and weaknesses. Lack of either set of knowledge might result in defeat. A certain school of thought draws parallels between the challenges in business and those of war, specifically:

- collecting data - both internal and external

- discerning patterns and meaning in the data (analyzing)

- responding to the resultant information

Prior to the start of the Information Age in the late 20th century, businesses sometimes took the trouble to laboriously collect data from non-automated sources. As they lacked computing resources to properly analyze the data, they often made commercial decisions primarily on the basis of intuition.

As businesses started automating more and more systems, more and more data became available. However, collection often remained a challenge due to a lack of infrastructure for data exchange or due to incompatibilities between systems. Reports on the data gathered sometimes took months to generate. Such reports allowed informed long-term strategic decision-making. However, short-term tactical decision-making often continued to rely on intuition.

In 1989 Howard Dresner, a research analyst at Gartner, popularized business intelligence (BI) as an umbrella term to describe a set of concepts and methods to improve business decisionmaking by using fact-based support systems. Performance Management builds on a foundation of $\mathrm{BI}$, but marries it to the planning and control cycle of the enterprise - with enterprise planning, consolidation and modeling capabilities.

Increasing standards, automation, and technologies have led to vast amounts of data becoming available. Data warehouse technologies have set up repositories to store this data. Improved ETL (extract, transform load) and Enterprise Application Integration tools have increased the speedy collecting of data. OLAP (online analytical process) reporting technologies have allowed faster generation of new reports which analyze the data. As of 2010, business intelligence has become the art of sieving through large amounts of data, extracting useful information and turning that information into actionable knowledge.

\section{Definition and scope}

Corporate performance management consists of a set of management and analytic processes, supported by technology, that enable businesses to define strategic goals and then measure and manage performance against those goals. Core business performance management processes include financial planning, operational planning, consolidation and reporting, business modeling, analysis, and monitoring of key performance indicators linked to strategy.

Corporate performance management involves consolidation of data from various sources, querying, and analysis of the data, and putting the results into practice.

\section{Methodologies}

Various methodologies for implementing corporate performance management exist. The discipline gives companies a top-down framework by which to align planning and execution, strategy and tactics, and business-unit and enterprise objectives. Reactions may include the Six 
Sigma strategy, balanced scorecard, activity-based costing (ABC), Total Quality Management, economic value-add, integrated strategic measurement and Theory of Constraints.

The balanced scorecard is the most widely adopted performance management methodology. There I will briefly discuss the balanced scorecard and SWOT analysis as the part of performance methodologies.

Methodologies on their own cannot deliver a full solution to an enterprise's CPM needs. Many pure-methodology implementations fail to deliver the anticipated benefits due to lack of integration with fundamental CPM processes.

Metrics / key performance indicators

Some of the areas from which top management analysis may gain knowledge by using business performance management may include:

1. customer-related numbers:

1. new customers acquired

2. status of existing customers

3. attrition of customers (including breakup by reason for attrition)

2. turnover generated by segments of the customers - possibly using demographic filters

3. outstanding balances held by segments of customers and terms of payment - possibly using demographic filters

4. collection of bad debts within customer relationships

5. demographic analysis of individuals (potential customers) applying to become customers, and the levels of approval, rejections and pending numbers

6. delinquency analysis of customers behind on payments

7. profitability of customers by demographic segments and segmentation of customers by profitability

8. campaign management

9. real-time dashboard on key operational metrics

1. overall equipment effectiveness

10. clickstream analysis on a website

11. key product portfolio trackers

12. marketing-channel analysis

13. sales-data analysis by product segments

14. callmcenter metrics

The above list more or less describes what a bank might monitor, but could also refer to a telephone company or to a similar service-sector company.

Items of generic importance might include:

1. consistent and correct KPI-related (key performance indicator) data providing insights into operational aspects of a company

2. timely availability of KPI-related data

3. KPIs designed to directly reflect the efficiency and effectiveness of a business

4. information presented in a format which aids decision-making for management and decision-makers

5. ability to discern patterns or trends from organized information

Corporate performance management integrates the company's processes with CRM (customer relationship management or ERP (enterprise resource planning). Companies should become better able to gauge customer satisfaction, control customer trends and influence shareholder value. 


\section{Application software types}

People working in business intelligence have developed tools that ease the work of corporate performance management, especially when the business-intelligence task involves gathering and analyzing large amounts of unstructured data.

Tool categories commonly used for business performance management include:

- OLAP — online analytical processing, sometimes simply called "analytics" (based on dimensional analysis and the so-called "hypercube" or "cube")

- scorecarding, dashboarding and data visualization

- data warehouses

- document warehouses

- text mining

- DM — data mining

- $\mathrm{BPO}$ - business performance optimization

- $\mathrm{EPM}$ - enterprise performance management

- EIS - executive information systems

- DSS - decision support systems

- MIS - management information systems

- SEMS - strategic enterprise management software

- business dashboards

\section{Design and implementation}

Issues when implementing a business performance management program might include:

- Goal-alignment queries: one must first determine the short- and medium-term purpose of the program. What strategic goal(s) of the organization will the program address? What organizational mission/vision does it relate to? A hypothesis needs to be crafted that details how this initiative will eventually improve results / performance (i.e. a strategy map).

- Baseline queries: current information-gathering competency needs assessing. Does the organization have the capability to monitor important sources of information? What data is being collected and how is it being stored? What are the statistical parameters of this data, e.g., how much random variation does it contain? Is this being measured?

- Cost and risk queries: someone should estimate the financial consequences of a new BI initiative. It is necessary to assess the cost of the present operations and the increase in costs associated with the BPM initiative. What is the risk that the initiative will fail? This risk assessment should be converted into a financial metric and included in the planning.

- Customer and stakeholder queries: determine who will benefit from the initiative and who will pay. Who has a stake in the current procedure? What kinds of customers / stakeholders will benefit directly from this initiative? Who will benefit indirectly? What quantitative / qualitative benefits follow? Is the specified initiative the best or only way to increase satisfaction for all kinds of customers? How will customer benefits be monitored? What about employees, shareholders, and distribution channel members?

- Metrics-related queries: information requirements need operationalization into clearly defined metrics. One must decide what metrics to use for each piece of information being gathered. Are these the best metrics? How do we know that? How many metrics need to be tracked? If this is a large number (it usually is), what kind of system can track them? Are the metrics standardized, so they can be benchmarked against performance in other organizations? What are the industry standard metrics available?

- Measurement methodology-related queries: one should establish a methodology or a procedure to determine the best (or acceptable) way of measuring the required metrics. How frequently will data be collected? Are there any industry standards for this? Is this the best way to do the measurements? How do we know that? 
- Results-related queries: someone should monitor the BPM program to ensure that it meets objectives. The program itself may require adjusting. The program should be tested for accuracy, reliability, and validity. How can it be demonstrated that the BI initiative, and not something else, contributed to a change in results? How much of the change was probably random?

\section{Performance analysis}

Performance analysis is the systematic diagnosis of how a business, a department or an individual is performing in terms of both performance drivers and brakes.

Performance analysis is an essential skill for any general manager with profit responsibility. It is also important for financial managers, who still need to diagnose the performance of their support departments.

Performance analysis is needed:

- before the event, what will the key performance drivers be (in advance), for business planning purposes,

- during the event, to understand, and learn from current business performance, and to take immediate action (if appropriate/feasible), and

- after the event, for learning and feedback, and for input into new business plans.

A key technique for performance analysis is that of key performance drivers. Performance driver analysis helps to diagnose organizational performance, either externally or internally, or both. A second way of analyzing business and financial performance is to identify the key performance drivers using a vector format.

Performance driver analysis can be used for:

- analyzing a group's performance,

- understanding a business unit's performance,

- understanding a team's performance, and

- analyzing an individual's performance.

Performance driver analysis is especially helpful in turnaround situations. In many ways, performance driver analysis is more incisive than strengths and weaknesses, opportunities and threats (SWOT) analysis, as it focuses on those factors that have an impact on economic value generation in a business. This gets us away from the 'nice-to-haves', which often cloud up the 'strengths' of SWOT analysis. Also, with the vector format, the performance drivers are automatically prioritized. The pros of performance driver analysis are:

- the 'so-what?' drops out much more readily than in a SWOT analysis,

- it is already prioritized,

- $\quad$ it can be linked more closely to financial planning,

- it gives a better feel of the overall business context before addressing a specific business problem or bottleneck (so that we do not simply respond reactively to a problem),

- it makes judgments on performance less of a personal issue, and

- it can distinguish (in separate analysis) external and internal performance drivers.

In addition it may be useful to translate this analysis into a set of indicators, sometimes called KPIs or 'key performance indicators'. These lists, the measures/indicators against which success will be judged.

In reality, very few if any of these KPIs were ever realized. A related approach is the balanced scorecard.

\section{SWOT analysis}

SWOT analysis is a strategic planning method used to evaluate the Strengths, Weaknesses, Opportunities, and Threats involved in a project or in a business venture. It involves specifying the objective of the business venture or project and identifying the internal and external factors that are 
favorable and unfavorable to achieve that objective. The technique is credited to Albert Humphrey, who led a convention at Stanford University in the 1960s and 1970s using data from Fortune 500 companies.

A SWOT analysis must first start with defining a desired end state or objective. A SWOT analysis may be incorporated into the strategic planning model. Strategic planning has been the subject of much research.

- Strengths: attributes of the person or company those are helpful to achieving the objective(s).

- Weaknesses: attributes of the person or company those are harmful to achieving the objective(s).

- Opportunities: external conditions those are helpful to achieving the objective(s).

- Threats: external conditions which could do damage to the objective(s).

Identification of SWOTs are essential because subsequent steps in the process of planning for achievement of the selected objective may be derived from the SWOTs. First, the decision makers have to determine whether the objective is attainable, given the SWOTs. If the objective is NOT attainable a different objective must be selected and the process repeated. The SWOT analysis is often used in academia to highlight and identify strengths, weaknesses, opportunities and threats. It is particularly helpful in identifying areas for development.

\section{Matching and converting}

Another way of utilizing SWOT is matching and converting. Matching is used to find competitive advantages by matching the strengths to opportunities. Converting is to apply conversion strategies to convert weaknesses or threats into strengths or opportunities. An example of conversion strategy is to find new markets. If the threats or weaknesses cannot be converted a company should try to minimize or avoid them.

\section{Evidence on the use of SWOT}

SWOT analysis may limit the strategies considered in the evaluation. J. Scott Armstrong notes that "people who use SWOT might conclude that they have done an adequate job of planning and ignore such sensible things as defining the firm's objectives or calculating ROI for alternate strategies. Findings from Menon et al. (1999) and Hill and Westbrook (1997) have shown that SWOT may harm performance. As an alternative to SWOT, Armstrong describes a 5-step approach alternative that leads to better corporate performance.

\section{Internal and external factors}

The aim of any SWOT analysis is to identify the key internal and external factors that are important to achieving the objective. These come from within the company's unique value chain. SWOT analysis groups key pieces of information into two main categories:

- Internal factors - The strengths and weaknesses internal to the organization.

- External factors - The opportunities and threats presented by the external environment to the organization. - Use a PEST or PESTLE analysis to help identify factors

The internal factors may be viewed as strengths or weaknesses depending upon their impact on the organization's objectives. What may represent strengths with respect to one objective may be weaknesses for another objective. The factors may include all of the 4P's; as well as personnel, finance, manufacturing capabilities, and so on. The external factors may include macroeconomic matters, technological change, legislation, and socio-cultural changes, as well as changes in the marketplace or competitive position. The results are often presented in the form of a matrix.

SWOT analysis is just one method of categorization and has its own weaknesses. For example, it may tend to persuade companies to compile lists rather than think about what is actually important in achieving objectives. It also presents the resulting lists uncritically and without clear prioritization so that, for example, weak opportunities may appear to balance strong threats.

It is prudent not to eliminate too quickly any candidate SWOT entry. The importance of individual SWOTs will be revealed by the value of the strategies it generates. A SWOT item that 
produces valuable strategies is important. A SWOT item that generates no strategies is not important.

\section{Use of SWOT Analysis}

The usefulness of SWOT analysis is not limited to profit-seeking organizations. SWOT analysis may be used in any decision-making situation when a desired end-state (objective) has been defined. Examples include: non-profit organizations, governmental units, and individuals. SWOT analysis may also be used in pre-crisis planning and preventive crisis management. SWOT analysis may also be used in creating a recommendation during a viability study/survey.

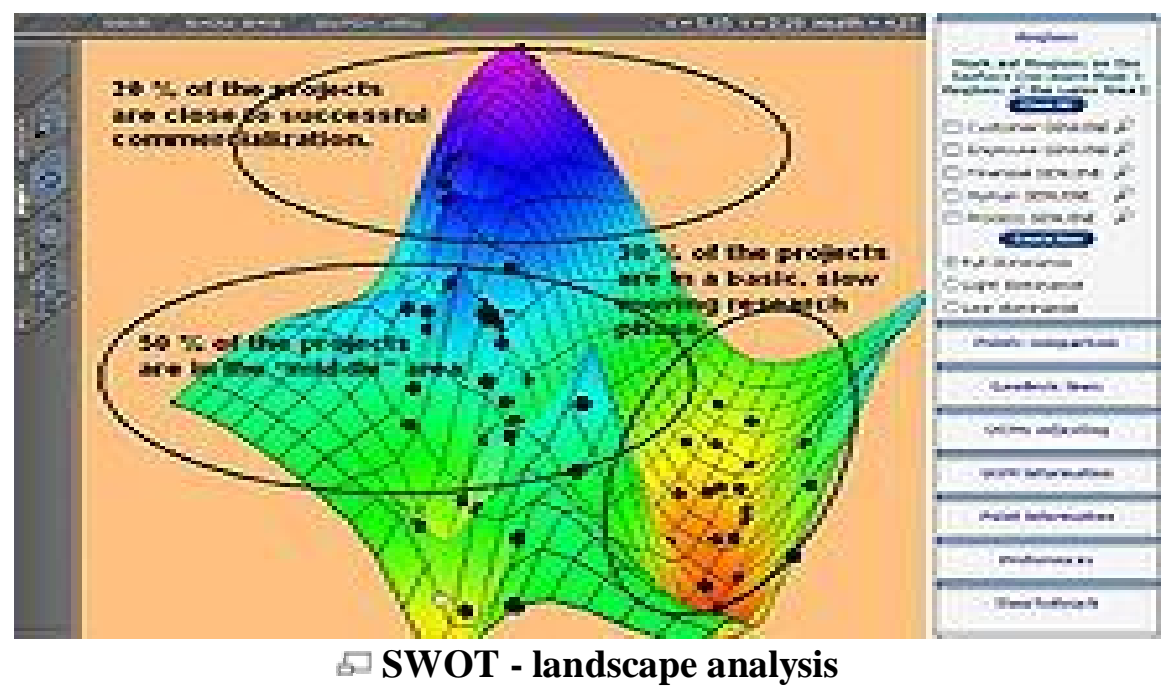

The SWOT-landscape systematically deploys the relationships between overall objective and underlying SWOT-factors and provides an interactive, query-able 3D landscape.The SWOTlandscape grabs different managerial situations by visualizing and foreseeing the dynamic performance of comparable objects according to findings by Brendan Kitts, Leif Edvinsson and Tord Beding (2000).Changes in relative performance are continually identified. Projects (or other units of measurements) that could be potential risk or opportunity objects are highlighted. SWOTlandscape also indicates which underlying strength/weakness factors that have had or likely will have highest influence in the context of value in use (for ex. capital value fluctuations).

\section{Corporate planning}

As part of the development of strategies and plans to enable the organization to achieve its objectives, then that organization will use a systematic/rigorous process known as corporate planning. SWOT alongside PEST/PESTLE can be used as a basis for the analysis of business and environmental factors.

- Set objectives - defining what the organization is going to do

- Environmental scanning

- Internal appraisals of the organization's SWOT, this needs to include an assessment of the present situation as well as a portfolio of products/services and an analysis of the product/service life cycle

- Analysis of existing strategies, this should determine relevance from the results of an internal/external appraisal. This may include gap analysis which will look at environmental factors

- Strategic Issues defined - key factors in the development of a corporate plan which needs to be addressed by the organization 
- Develop new/revised strategies - revised analysis of strategic issues may mean the objectives need to change

- Establish critical success factors - the achievement of objectives and strategy implementation

- Preparation of operational, resource, projects plans for strategy implementation

- Monitoring results - mapping against plans, taking corrective action which may mean amending objectives/strategies.

Key points for performance drivers are:

- Ask: what is the one big thing you have forgotten? (In Rovers case the initial sterling exchange rate at the time of acquisition negotiations subsequently strengthened by $20 \%$, impacting hugely on both sales volumes and margins.)

- Also ask: what is the second big thing you have forgotten? (Again, in Rover, investment levels had to be trebled to develop a truly competitive range of cars.)

\section{Balanced card and EVA}

Many companies are using a Balanced Scorecard (BSC) and Economic Value Added (EVA) as a way to measure performance. I will provide a summary of both to determine if BSC or EVA is the better way for a company to determine performance.

Organizations need to be able to measure their financial and non-financial performance. The balanced scorecard is one way to measure the organizations past, current, and future goals and objectives and puts them into a set of performance measures that is easy to understand (Horngren, Sundem, Stratton, and Burgstahler, Schatzberg, 2008). A balanced scorecard is used to evaluate performance from the following four objectives:

- Learning and growth - It is very important to have qualified educated employees within an organization. We need to determine if our employees are trained and if there are any areas where they may need improvement.

- Internal business - Managers need to ask themselves if the organization is satisfying both the shareholders and their customers. This will help management determine how well the business is running.

- Customer values - It is important that our customers are satisfied. Companies will often send out a customer satisfaction survey to determine if customers are happy with the suppliers performance. Some areas that may be measured would be customer service or on time delivery of the product.

- Financial - It is very important to have up to date accounting information for our stockholders. We need to determine how we are going to make money in order to be a profitable company (BSC Resources, 2008).

More managers are choosing to apply the balanced scorecard because financial measures such as Return on Investment (ROI) are not sufficient enough to determine how an organization is performing (Horngren, Sundem, Stratton, and Burgstahler, Schatzberg, 2008).

Economic Value Added, or "economic profit", measures an organization's true profit after all the cost of invested capital is deducted from this number. EVA helps managers improve their decision making about a person, project, department, or company. The formula is EVA $=$ adjusted after-tax operating income $-($ after-tax cost of invested capital (\%) x average invested capital). A positive EVA means that value has been added to the company for the shareholders. A negative EVA means that the company has not contributed to the value of the organization (Harper, 2008).

Managers can increase EVA by:

- increasing revenue

- minimizing operating expenses

- producing the same goods and services using less capital 
- investing only in projects that will be productive

- reducing the cost of capital

\section{Balanced scorecard}

The balanced scorecard was developed to provide and measure performance as compared to the organization's objectives, providing feedback and serving as an indicator of overall organizational efficacy. The balanced scorecard typically includes four different performance classifications: financial perspective, customer perspective, internal business processes, and learning and growth, or the development perspective (CTU Online, 2008 and Garrison, Noreen, \& Brewer, 2008).

An organization's strategy and value proposition provide the standard of measure by which the different elements of the balanced scorecard are compared. Measures closely aligned with organizational strategy are created by management and communicated to employees to ensure everyone understands what is expected and to provide a point of reference for decision-making applications (Garrison, et al.). In an effort to gauge the effectiveness of strategy implementation and to provide a comparison between actual and planned organizational performance, a good set of performance measures will facilitate an organization-wide focus on those elements that define and support success, provide a common language for those in all levels of the organization through explicit and relevant terms, ensures measurement of appropriate activities, and provides verifiable data (Balanced Scorecard Institute, 2007).

Financial performance measures and standards must be viewed and created alongside qualitative data as maximizing profits is not always the number one goal of production. Although all organization's seek to increase value, some will seek to increase value while maintaining a greater focus on providing newest technologies, most environmentally friendly products, or most excellent customer service and the additional resources consumed by those commitments will cause variances in financial performance and must be taken into consideration when analyzing overall performance. The financial performance of the balanced scorecard will provide more of a historic view at performance and success whereas the remaining, nonfinancial measures are more forward-looking as they relate to planning and operations. Common financial data found in the balanced scorecard include standard costs, measures of income, return on investment, or residual income, all providing specific points of measure and points of reference for creating or adjusting strategy (Edmonds, Edmonds, Tsay \& Olds, 2006). Risk assessment, cost benefit, and other financial data can also be included in financial performance measures due to the necessity for timely and accurate funding data, but must always be viewed in balance or with respect to the other factors of measurement (Kaplan \& Norton, 2008).

The customer perspective identifies specific target customer segments in the organization's respective industry and specifies expectant and/or desired business unit performance in those consumer segments. Numerous measures, both quantitative and qualitative, are used to formulate and communicate useful customer data information to facilitate a well-developed strategy. Those measures include customer satisfaction and retention, customer acquisition and profitability, market share, and account share. Objectives relative to these different items of measure are used alongside objectives and measures outlined in the value proposition. Value proposition may focus on lowest costs, or best buy, product innovation and industry leadership, or complete customer solutions. Customer perspective cannot be directly addressed without understanding exactly what customers expect, or are guaranteed through the value proposition (Atkinson, et al.). This provides the appropriate direction in strategy formation, as it applies to addressing the needs, satisfying, attaining, and sustaining a strong customer base.

Internal business processes refer to the activities within the organization that occur in an attempt to satisfy and meet customer expectations. With realization of financial and customer objectives, the organization now has the data necessary to identify and adjust the internal processes 
that will directly impact those objectives. Identifying financial and customer objectives provides an expected performance reference point by which management can determine how it will produce and deliver the value proposition for its customers and achieve the productivity requirements necessary for attaining financial objectives. This internal perspective pinpoints critical processes the organization must excel at to achieve strategical objectives and are generally classified into four separate process groupings: operating processes, customer management, innovation, and regulatory and social processes (Atkinson, et al.).

Operating processes represent the daily processes by which the company produces and delivers their current products and services. Operating processes include raw material acquisition, conversion of raw materials into finished goods, and distribution of those goods to the customer. Performance objectives and measures can be applied to each of these processes by management, and resulting modifications to costs, quality, and process times will ensue with changes aimed at improvement based on the applied performance objectives. Similarly, specific customer management processes such as selection, acquisition, retention and growth are provided specific performance objectives from which adjustments to those processes will provide for continual improvement and alignment with specific process-related goals. The innovation processes represent development of new products, processes and services that enable the organization to penetrate new markets and customer segments and drive customer acquisition, loyalty and growth. Through an improved customer dynamic, the innovation process further serves to enhance the profit margin. Appropriate management of innovation processes includes identification of opportunity for new services and products, effectively managing the R \& D portfolio, design and development of new products and services and successful market introduction. Regulatory and social processes refer to the organizations right to operate within the communities they produce and sell. National and local regulations relative to environment, health and safety, employment practices, and community investment all have the potential to increase or decrease value of the organization according to practice and compliance with these regulations. Those regulatory and social processes require effective management and attention that equals the other business processes as recovery from the consequences of non-compliance could prove unrecoverable (Atkinson, et al.).

It is widely realized that continuing education or learning is essential to consistently improving upon efficacy and remaining competitive. Thus learning or development is the underlying idea that drives the different elements of measure that provide a balanced view of organizational effectiveness (Garrison, et al.). The learning and growth perspective addresses specific capabilities or competencies of employees or divisions, capabilities and availability of the information and communications system employed in the organization, the organizational climate or culture, and any other process within the organization that directly influences the relationship with the customer and facilitates long-term growth and improvement. The internal perspective provided by the balanced scorecard helps management to identify exactly where resources must be invested to improve employee skills, or enhance any of the other areas of internal business processes that require improvement to maximize on successful strategy implementation. This element of the scorecard communicates specifically how well the organization's intangible assets and managed and leveraged to drive improvement (Atkinson, Kaplan, \& Young, 2004). Recognizing that change is inevitable and the organization must be open to and must effectively manage change to remain successful, the learning and growth perspective allows for identification of the areas that might require change or improvement, and ensures the elements of successful change management are realized, employed, and embedded within the organization's culture.

For the organization, the balanced scorecard serves as a customer based planning and improvement tool used with the intent to drive necessary organizational changes to strategy to assist the organization in sustaining competitiveness and ensuring operations are focused in the direction of success as it relates to specified strategical measures. Using financial and nonfinancial measures, objective and subjective measures, the balanced scorecard effectively 
communicates performance objectives in numerous areas to the relevant divisions and individuals who can provide feedback and assist in developing and implementing change ideas. Use of the balanced scorecard is said to have many beneficial effects on the organization including promotion of active formulation and implementation of organization strategy, keeps strategies updated and highly visible, improves overall system of communications within the organization, improves goal alignment among the many different departmental and divisional elements of the organization, aligns the short-term plans for operations with long-term goals, and aligns performance measures with long-term strategic goals (Pineno, 2004).

Many companies are now using both EVA and the BSC. EVA is a good way to determine financial performance and BSC is a good way to determine not only financial performance of an organization, but the non-financial performance of the organization as well (Jalbert, Landry, 2003).

\section{Financial ratio}

All financial statements are essentially historically historical documents. They tell what has happened during a particular period of time. However most users of financial statements are concerned about what will happen in the future. Stockholders are concerned with future earnings and dividends. Creditors are concerned with the company's future ability to repay its debts. Managers are concerned with the company's ability to finance future expansion. Despite the fact that financial statements are historical documents, they can still provide valuable information bearing on all of these concerns.

Financial statement analysis involves careful selection of data from financial statements for the primary purpose of forecasting the financial health of the company. This is accomplished by examining trends in key financial data, comparing financial data across companies, and analyzing key financial ratios.

Managers are also widely concerned with the financial ratios. First the ratios provide indicators of how well the company and its business units are performing. Some of these ratios would ordinarily be used in a balanced scorecard approach. The specific ratios selected depend on the company's strategy. For example a company that wants to emphasize responsiveness to customers may closely monitor the inventory turnover ratio. Since managers must report to shareholders and may wish to raise funds from external sources, managers must pay attention to the financial ratios used by external inventories to evaluate the company's investment potential and creditworthiness.

Although financial statement analysis is a highly useful tool, it has two limitations. These two limitations involve the comparability of financial data between companies and the need to look beyond ratios. Comparison of one company with another can provide valuable clues about the financial health of an organization. Unfortunately, differences in accounting methods between companies sometime make it difficult to compare the companies' financial data. For example if one company values its inventories by the LIFO method and another firm by average cost method, then direct comparisons of financial data such as inventory valuations are and cost of goods sold between the two firms may be misleading. Some times enough data are presented in foot notes to the financial statements to restate data to a comparable basis. Otherwise, the analyst should keep in mind the lack of comparability of the data before drawing any definite conclusion. Nevertheless, even with this limitation in mind, comparisons of key ratios with other companies and with industry averages often suggest avenues for further investigation.

An inexperienced analyst may assume that ratios are sufficient in themselves as a basis for judgment about the future. Nothing could be further from the truth. Conclusions based on ratio analysis must be regarded as tentative. Ratios should not be viewed as an end, but rather they should be viewed as a starting point, as indicators of what to pursue in greater depth. They may raise questions, but they rarely answer any question by themselves. In addition to ratios, other sources of data should be analyzed in order to make judgments about the future of an organization. 
They analyst should look, for example, at industry trends, technological changes, changes in consumer tastes, changes in broad economic factors, and changes within the firm itself. A recent change in a key management position, for example, might provide a basis for optimism about the future, even though the past performance of the firm may have been mediocre.

Few figures appearing on financial statements have much significance standing by themselves. It is the relationship of one figure to another and the amount and direction of change over time that are important in financial statement analysis. How does the analyst key in on significant relationship? How does the analyst dig out the important trends and changes in a company? Three analytical techniques are widely used; dollar and percentage changes on statements, common-size statements, and accounting ratios.

\section{References:}

1. Armstrong. M. A handbook of Human Resource Management Practice (10th edition) 2006. Kogan Page , London ISBN 0-7494-4631-5

2. Armstrong.M Management Processes and Functions, 1996. London CIPD ISBN 0-85

3. Atkinson, A.A., Kaplan, R.S., and Young, S.M., 2004. Management accounting, a custom Balanced Scorecard Institute, 2007. Performance measurement. Balanced Scorecard Institute. http://www.balancedscorecard.org/BSCResources/PerformanceMeasurement/tabid/59/

4. Brendan Kitts, Leif Edvinsson and Tord Beding, 2000. Crystallizing knowledge of historical company performance into interactive, query-able 3D Landscapes http://de.scientificcommons.org/534302

5. Edm Harper, D. (n.d.), 2008. Investopedia [EVA]. Retrieved November 29, from http://www.investopedia.com/university/EVA/

6. Hill, T. \& R. Westbrook, 1997. SWOT Analysis: It's Time for a Product Recall, Long Range Planning 30 (1): 46-52. doi:10.1016/S0024-6301(96)00095-7.

7. J. Scott Armstrong, 1982. The Value of Formal Planning for Strategic Decisions, Strategic Management Journal 3: 197-211. doi:10.1002/smj.4250030303.

8. Horngren, C.T., Sundem, G.L., Stratton, W.O., Burgstahler, D., Schatzberg, J., 2008. Introduction to Management Accounting ( $14^{\text {th }}$ Edition) Pearson, Prentice Hall, Upper Saddle River, NJ.

9. Jalbert, T., \& Landry, S. P., 2003. Spring. Which performance measurement is best for your company? Management Accounting Quarterly. Retrieved November 20, 2008, from http://findarticles.com/p/articles/mi_m0OOL/is_3_4/ai_105997565/pg_8 onds, T.P., Edmonds, C.D., Tsay, B.Y., and Olds, P.R. , 2006, Fundamental managerial.

10. Kaplan, R. and Norton, D., 2008. The BSC: translating strategy into action. Retrieved on June http://www.valuebasedmanagement.net/methods_balancedscorecard.html

11. Mehta, S., 2000. Marketing Strategy

12. Menon, A. et al., 1999. Antecedents and Consequences of Marketing Strategy Making, Journal of Marketing (American Marketing Association) 63(2) (2): 18-40. doi:10.2307/1251943. http://jstor.org/stable/1251943.

13. Pineno, C.J. 2004. Balanced scorecard applications and model building. Management 